\title{
Ecometrics: A trait-based approach to paleoclimate and paleoenvironmental reconstruction
}

\section{Vermillion, Wesley}

Springer

2018

Vermillion, W , Polly , P D , Head , J , Eronen , J \& Lawing , A M 2018 , Ecometrics: A trait-based approach to paleoclimate and paleoenvironmental reconstruction . in D A Croft , S W Simpson \& D F Su (eds), Methods in Paleoecology: Reconstructing Cenozoic Terrestrial Environments and Ecological Communities . Vertebrate Paleobiology and Paleoanthropology Series , Springer , pp. 373-394 . https://doi.org/10.1007/978-3-319-94265-0

http://hdl.handle.net/10138/325780

https://doi.org/10.1007/978-3-319-94265-0

unspecified

acceptedVersion

Downloaded from Helda, University of Helsinki institutional repository.

This is an electronic reprint of the original article.

This reprint may differ from the original in pagination and typographic detail.

Please cite the original version. 
1 Ecometrics: A Trait-based Approach to Paleoclimate and Paleoenvironmental

2 Reconstruction

4 Wesley A. Vermillion ${ }^{1}$, P. David Polly ${ }^{2}$, Jason J. Head ${ }^{3}$, Jussi T. Eronen ${ }^{4,5}$, A. Michelle

5 Lawing $^{1 *}$

6

$7 \quad{ }^{1}$ Ecosystem Science and Management, Texas A\&M University, College Station, TX,

8 USA

$9{ }^{2}$ Geological Sciences, Biology and Anthropology, Indiana University, Bloomington, IN,

10 USA

$11{ }^{3}$ Zoology, University of Cambridge, Cambridge, UK CB23EJ

$12{ }^{4}$ Department of Geosciences and Geography, University of Helsinki and BIOS Research

13 Unit, Helsinki, Finland

14

$15 *$ alawing@tamu.edu

16

17 Keywords: Functional morphology, Paleoecology, Maximum likelihood, Geographic

18 Distribution, Taxon-free

19

20 Suggested running head: Ecometrics: a trait-based approach

21 
24 Ecometrics is a trait-based approach to study ecosystem variability through time.

25 An ecometric value is derived from describing the distribution of functional traits at the

26 community level, which may arise by environmental filtering, extinction, or convergence.

27 An ecometric relationship describes the correspondence between spatially explicit

28 ecometric values and corresponding environmental variation. Transfer functions and

29 maximum likelihood approaches have been developed with modern trait-environment

30 relationships to reconstruct paleotemperature, paleoprecipitation, and paleovegetation

31 cover given the distribution of functional traits within a community. Because the focus

32 for this approach is on the traits and not on species, it is transferable through space and

33 time and can be used to compare no-analog communities. In this paper we review the

34 concepts and history of ecometric analysis and then describe practical methods for

35 implementing an ecometric study. 
37 One of the factors that sort species geographically into communities is the

38 filtering of species by their functional morphologies along climate and environmental

39 gradients (e.g., mammalian herbivores with higher molars eat more gritty and abrasive

40 vegetation and therefore more species with higher molars live in places with more gritty

41 and abrasive vegetation), thus, the morphology has a direct relationship with its

42 environmental condition. In this sorting process, the distribution of functional traits

43 within a community moves toward an optimal environmental condition. These functional

44 traits may be described in terms of their distributions within a community and descriptors

45 of the distribution of community level functional traits have been defined as ecometrics

46 (Eronen et al. 2010a; Polly et al. 2011). Thus, ecometrics are traits described at the

47 community level that have a relationship with environmental condition. Ecometrics are

48 spatially variable, because the composition of species and traits in communities vary

49 through geography. If species are perfectly sorted, the trait distributions in communities

50 will parallel variation in the environmental condition to which the traits are functionally

51 linked (i.e. the ecometric correlation equals one). If the ecometric correlation is strong,

52 one can estimate the most likely environmental condition given a specific ecometric

53 value using a transfer function or likelihood estimation. If the ecometric correlation is not

54 strong, one may still be able to estimate the most likely environmental condition, but the

55 likelihood surface would be more flat, which would produce a more ambiguous

56 reconstruction. The power of this approach is that functional trait measurements are

57 transferable through space and through time, regardless of the specific species that make

58 up the community. For this reason, ecometrics is a useful approach to reconstruct 
59 paleoclimate and paleoenvironment (Damuth et al. 1992).

\section{TERMS}

61 Functional trait - a behavioral, biochemical, morphological, phenological,

62 physiological, or structural characteristic that has a physical or chemical interaction with

63 a specific environmental factor. This characteristic is expressed as a phenotype of

64 individual organisms and it is considered relevant to the response of organisms to the

65 surrounding abiotic conditions. A functional trait is something that can be observed and

66 measured.

67 Geographic sorting - the process by which trait distributions are arranged in geographic

68 space along gradients of environmental conditions.

69 Taxon free - not depending on taxonomic identity (i.e. it is a descriptor based on trait

70 values rather than on presence or absence of particular taxa). For example, using palms as

71 indicators of frost-free conditions is a taxon-based approach, whereas using counts of

72 stomatal density as indicators of carbon dioxide concentration is a taxon-free approach

73 (Beerling et al. , 2011).

74 Ecometric value - a statistic summarizing the distribution of a functional trait within a

75 community at a single geographic location. Means, variances, proportions, and extremes

76 have been used as descriptors in previous studies; however, any parameter that describes

77 a distribution of functional traits may be used.

78 Ecometric patterning - geography, or spatial variation, of ecometric values across

79 communities. Perfect patterning represents optimal distributions of populations and

80 species. The lack of patterning could represent a lack of useable covariation, a mismatch

81 between the trait and the environment, or it could result from the inappropriate choice of 
82 environmental correlates.

83 Ecometric correlation - product-moment correlation between ecometric variation and

84 variation in the environmental condition. High correlations evince a close match between

85 the functional requirements of local communities and their abiotic condition.

86 Ecometric likelihood - the probability of finding a particular environmental condition

87 given the ecometric value of a community at any single geographic location.

88 Ecometric load - the amount of mismatch between the distribution of functional traits

89 and the selective optimum for the local environment. High loads may indicate risk to

90 changing environmental conditions. Note that high ecometric loads can be present even

91 with high ecometric correlations if traits are weakly but consistently sorted.

92 Ecometric optimum - the optimal distribution of an ecometric trait in a particular

93 environment. The optimum is more likely to be a distribution rather than a single trait

94 value, especially in locally heterogeneous environments (e.g., a savannah habitat favors

95 both large and small body sizes).

96 Transfer function - a function that represents the relationship between the ecometric trait

97 values and a relevant environmental variable.

\section{THEORETICAL AND HISTORICAL BACKGROUND}

Functional traits are features that organisms use to interact with their environment

102 and with other organisms (Diaz and Cabido 2001; Violle et al. 2007). Functional traits of

103 species within a community ultimately mediate the relationship between organisms'

104 morphology and their ecology and link organisms to biotic and abiotic conditions present 
105 at particular geographic locations at a particular point in time (Ricklefs and Travis 1980;

106 Chapin 1993; Poff 1997). A certain combination of biotic and abiotic conditions will thus

107 favor traits that maximize an organism's performance, either through natural selection or

108 geographic sorting. Natural selection is an evolutionary process that acts on the variation

109 in a population, where individuals that thrive in their environment produce the most

110 offspring and disproportionately share their traits with the next generation (Darwin and

111 Wallace 1858). Species that move geographically in response to environmental change

112 may follow an environment for which they are already adapted and form new

113 assemblages as a result (Jackson and Overpeck 2000). We are not concerned with the

114 trait values of particular species, but with the distribution of traits within communities

115 (e.g., mean, standard deviation, and range; Damuth et al. 1992). Even weak sorting

116 processes can produce trait gradients at the community level, as has been demonstrated in

117 climate gradients in plant leaf traits (Wolfe 1979; Reich et al. 1997; Wilf 1997; Wright et

118 al. 2004; Royer et al. 2005; Wing et al. 2005; Cornwell and Ackerly 2009; Peppe et al.

119 2011), large mammalian herbivores dental traits (Janis and Fortelius 1988; Damuth et al.

120 1992; Fortelius et al. 2002; Mendoza et al. 2005; Damuth and Janis 2011; Eronen et al.

121 2010b, 2012), carnivoran locomotor traits (Polly 2010), snake locomotor traits (Lawing et

122 al. 2012), and mammal life history, physiological, and range traits (Lawing et al. 2016).

123 The study of functional traits that have a relationship with climate or environmental

124 gradients at the community level has been termed ecometrics to distinguish it from

125 ecomorphology of particular species or clades (Eronen et al. 2010a; Polly et al. 2011).

126 Figure 1 shows a few examples of the morphology of ecometric traits. 
130 The relationship between the distribution of functional traits in a community and

131 the corresponding environmental factors in the local environment is likely to be complex.

132 Some trait-environment relationships favor a single ecometric optimum in each local

133 environment such that all species tend to have the same trait value. Stomatal density on

134 plant leaves might be expected to have a single optimal value across all members of a

135 community because carbon dioxide concentrations and evapotranspiration conditions are

136 the same for all. However, locally heterogeneous environments are likely to favor a

137 heterogeneous ecometric optimum. For example, savannah environments tend to favor a

138 combination of large body masses (for animals that can travel long distances to procure

139 food in a comparatively resource poor habitat and defend themselves in the open) and

140 small body masses (for species that can subsist on the resources found in a limited area

141 and can find cover in grasses or tree tops). The nature of the ecometric optimum will

142 dictate how it should be measured. An optimum that favors a single trait value can always

143 be adequately represented with the community mean, but an optimum that favors a

144 complex distribution may be better characterized by variance, skewness, or other

145 measure. Temporal variation in environmental conditions may also shape the distribution

146 of the ecometric optimum. For example, Žliobaitè et al. (2016) recently showed that

147 recurring extreme conditions (like drought) were better predictors of dental traits than

148 average conditions, indicating that recurring limiting conditions may be important drivers

149 of community functional trait distributions. 
151 Bailey and Sinnott (1915) conducted the first study of community-level functional

152 traits. They showed plant communities that have more leaves with ridges, or non-entire

153 margins, occur in moist temperate climates that experience warm summers and cold

154 winters. Conversely, plant communities that have leaves with no ridges, or entire leaf

155 margins, occur in dry climates including tropic, alpine and arctic regions, moors, steppes,

156 deserts, saline situations, and other physiologically dry climates. They used the

157 proportion of species within a community with a specified phenotype as their metric to

158 describe the community, what we refer to as an ecometric trait value.

159 Since Bailey and Sinnott (1915) demonstrated the variation in community leaf

160 shape across a temperature gradient, researchers have used leaf shape and other traits to

161 reconstruct paleotemperature. Most notably, Wolfe $(1979,1993)$ quantified the

162 relationship between leaf margins and temperature, which led to many quantitative

163 paleoclimate reconstructions from leaf assemblages, called leaf-margin analysis.

164 Contemporary to and since Wolfe's work, researchers have been interested in identifying

165 the function of leaf teeth (see Royer and Wilf (2006) for a history and discussion).

166 The ecometric approach has grown out of the formalization by Damuth et al.

167 (1992) of "taxon-free" characterizations of animal communities. These authors were

168 interested in understanding long-term evolutionary and ecological processes. They argued

169 that distributions of traits such as body size, dietary type, locomotor specialization, and

170 predator-to-prey ratios serve as descriptive indices that can be used to compare important

171 aspects of community function in the Paleozoic, Mesozoic, and Cenozoic or between

172 faunal and floral realms in a single time period, because they capture information about

173 productivity, resource availability, community physiognomy, and resource partitioning, 
174 comparisons that cannot be made if community function is characterized by the species

175 that dominate it (such as grassland communities). They noted that what makes an

176 approach "taxon-free" is the focus on distributions of traits for inferring

177 paleoenvironment (i.e., the ecometric distributions), not the inferential pathways that lead

178 to the understanding of the trait-environment relationship, which may be founded on

179 taxon-based observations. The fact that many traits have a limited phylogenetic

180 distribution (e.g., teeth are limited to vertebrates, leaf stomata are limited to plants)

181 means that taxon-free approaches, including ecometrics, are not completely free of time,

182 place, and taxon, but comparisons between communities that have no species in common

183 are nevertheless possible. Andrews and Hixson (2014) recently reviewed and critiqued

184 taxon-free approaches.

186 One of the best-understood ecometrics is the molar crown height of herbivorous

187 large mammals. Different diets vary in the amount of wear they produce: species that eat

188 abrasive or tough foods, or foods of poor nutritive quality, usually have hypsodont teeth,

189 which have a high crown relative to the root. Hypsodonty is a morphology adaptated to

190 high rates of tooth wear (Janis and Fortelius 1988). Proximal factors including

191 abrasiveness of plant material, such as phytolith content and ambient grit and dust, are

192 therefore likely to play a role in selection for tooth crown height (Janis and Fortelius,

193 1988; Strömberg et al. , 2013; Fortelius et al. , 2014). Tooth crown height correlates with

194 precipitation in the modern world and geologic past (Fortelius et al. 2002; Eronen et al.

195 2010a,b; Fortelius et al. 2014). Eronen et al. (2010b) used regression trees to show that

196 there is a strong correlation (65.8\%) between crown tooth height and regional 
197 precipitation, between diet and precipitation (66.5\%), and when diet and tooth crown

198 height are combined (74.2\%). Community hypsodonty levels, therefore, have a strong

199 correlation with annual precipitation, which affects both plant tissue properties and the

200 amount of local grit (Fortelius et al. 2014) and may be used as a paleoprecipitation proxy

201 that constrain regional details about vegetation patterns and climate models (Fortelius et

202 al. 2002).

203 Together with other dental traits, hyposodonty can additionally be used to

204 estimate more indirect properties like net primary productivity (Liu et al. , 2012) or more

205 proximate ones like production of volcanic ash (Strömberg et al. , 2013). Such complex

206 combinations of proximal and distal environmental factors are likely to be associated

207 with all ecometric traits (Polly and Head 2015). Žliobaite et al. (2016) showed that dental

208 traits are closely linked to vegetation greenness (NDVI) in addition to precipitation and

209 temperature. This is reassuring as NPP estimates used in Liu et al. (2012) are computed

210 using precipitation as an input and highly dependent on NPP. NDVI is a direct

211 observation of vegetation greenness and is independent of precipitation and temperature

212 measurements. The NDVI depends on climatic conditions and reflects NPP and thus the

213 availability and quality of herbivores' food. Using data from present-day seasonal

214 environments in Africa, Žliobaite et al. (2016) demonstrate that the dental traits show

215 strong correlations to non-availability of preferred plant foods (e.g., during dry seasons or

216 longer dry periods), rather than the properties of average foods consumed. This is the

217 main functional link between climate and herbivore teeth and closely follows the

218 suggestion by Owen-Smith (2002) (see also discussion in Liu et al. 2012 and Fortelius et

219 al. 2014). 
Other dental characteristics (such as dental wear patterns, dental structure, and

221 tooth crown complexity) have also been used as estimates of diet in mammals (Fortelius

222 and Solounias 2000; Evans et al. 2007; Eronen et al. 2010a; Wilson et al. 2012; Evans

223 2013; Saarinen 2014; Saarinen and Karme 2017). Wilson et al. (2012) used the dental

224 shape descriptor of orientation patch count (OPC), which is a measure of dental

225 complexity that correlates well with feeding ecology in extant mammals, to determine the

226 paleodiet of the extinct mammalian clade Multituberculata. They were able to identify a

227 shift from a more carnivorous or omnivorous diet among early multituberculates into a

228 more herbivorous diet around 85 million years ago. This shift coincided with the rise of

229 angiosperms. Since vegetation patterns are driven by climatic conditions, these other

230 dental characteristics could potentially be used as climatic proxies. Evans (2013)

231 reviewed dental shape descriptors, which can be used in ecometric studies and will be

232 useful for describing environmental conditions in the past.

233 Another well-studied trait in both endothermic and ectothermic vertebrates is

234 body size, initiated by the work of Bergmann (1947). Mean body size in non-flying

235 mammals has been shown to increase as temperature decreases, and therefore mean body

236 size increases geographically toward the poles (Rodriquez et al. 2008; Eronen et al.

237 2010a). It has also been documented in ectothermic animals that body size is positively

238 correlated with mean ambient temperature (Makarieva et al. 2005). This has allowed for

239 the use of ectothermic animals, to be used to estimate paleotemperatures (Head et al.

240 2009; Polly et al. 2011; Head et al. 2013). Examples of ecometrics in plants, birds,

241 mammals, and snakes are detailed in Table 1, showing the functional trait and the

242 environmental condition for which it is related. 
244 Table 1. Examples of ecometrics in plants, birds, mammals, and snakes.

245 Environmental conditions are mean annual temperature (MAT), annual

246 precipitation (AP), atmospheric carbon dioxide (pCO2), net primary productivity

247 (NPP), trophic position (TP), dietary classification (DC), and vegetation cover (VC).

\begin{tabular}{llll}
\hline Group & Functional Trait & Environmental & Citation \\
& & Condition & \\
\hline Plants & Leaf margin & MAT & Wolf 1979 \\
Plants & Leaf shape & MAT & Wolf 1990; Royer et al. \\
& & & 2005; Peppe et al. 2011 \\
Plants & Stomata counts & pCO2 & Beerling et al. 2002 \\
Birds & Body mass & MAT & Meiri and Dayan 2003 \\
Mammals & Body mass & MAT & Damuth et al. 1992 \\
Mammals & Tooth morphology & AP; TP; DC; NPP & Evans 2013 \\
Ungulates & Hypsodonty & AP & Fortelius et al. 2002 \\
Carnivorans & Limb proportion & VC; MAT; AP & Polly 2010 \\
Snakes & Body length & MAT & Head et al. 2009 \\
Snakes & Tail proportion & VC & Lawing et al. 2012 \\
\hline
\end{tabular}

250 Geographic sorting of traits along environmental gradients is one of three

251 processes by which ecometric patterning can emerge, along with evolutionary adaptation

252 and extinction (Polly et al. 2015). Environmental gradients are shown to filter species 
253 geographically (Belmaker and Jetz 2012). The filtering effects of environmental gradients

254 may sort species geographically by their traits, resulting in local communities with

255 similar trait values that are correlated with local environmental conditions. The ecometric

256 approach was formalized as a way of synthesizing data from the ecological present and

257 geological past to measure responses of ecosystems to climate change in order to better

258 predict the risks posed by global change over the next millennia (Eronen et al. 2010a;

259 Polly et al. 2011). It has been used to investigate the impacts and risk of extinction

260 (Wilson et al. 2012; Polly and Sarwar 2014; Polly and Head 2015) and to understand

261 non-ecological processes (Lawing et al. 2016). The relative roles of geographic sorting,

262 local adaptation, and extinction have been investigated by process-based simulation

263 (Polly et al. 2015). Ecometrics and its paleontological precursors have been used to

264 estimate paleobiotic conditions using traits (Damuth et al. 1992). For example, ecotherm

265 body size (Head et al. 2009; Head et al. 2013) and leaf shape (Wolfe 1993; Little et al.

266 2010) have been used as paleothermometers and tooth crown height, hyposodonty, has

267 been used to estimate paleoaridity (Fortelius et al. 2002).

268 The ecometric approach may be used to forecast community responses to

269 anthropogenic climate change (Barnosky et al. , 2017). The concept of ecometric load,

270 which is the mismatch between community-level functional trait values and optimal

271 performance, potentially allows us to estimate the vulnerability of a community to

272 climate or environmental change when the optimal performance of the traits along an

273 environmental gradient is known (Polly et al. 2015). If changing conditions increase the

274 ecometric load, communities are more likely to become vulnerable. 
276 have been expanded extensively. For example, Head et al. (2009) made a significant push

277 forward on the construction of ecometric models and the application of the transfer

278 function. Instead of solely using correlative models for inference, they used a mechanistic

279 model from the physiology of poikilothermic metabolism along with modern

280 observations of boid snakes and the temperatures they live in to predict paleotemperature

281 at 58-60 Ma (Paleocene) in the neotropics. They found a minimum mean annual

282 temperature of $30-34^{\circ} \mathrm{C}$ was needed in the Cerrejon Formation in Colombia during this

283 time in order for the large boid, Titanoboa, to survive. This is several degrees warmer

284 than the mean annual temperature of $26-27^{\circ} \mathrm{C}$ found in that area of the world.

285 The effects of faunal sampling, extinction, and extirpation on ecometric patterns

286 was investigated by Polly and Sarwar (2014) using resampling and rarefaction methods

287 with calcaneum gear ratios. Gear ratios are related to the locomotor style of an animal

288 and, in turn, related to the animal's habitat. Polly and Sarwar (2014) showed that

289 extinction, extirpation, and range change have minimal effects on ecometric correlations

290 when they affect less than a quarter of the species in North American carnivoran

291 communities. If the correlation between gear ratio and an environmental variable, such as

292 vegetation cover, is either high or low, then extinction of more than $25 \%$ of species will

293 alter the correlations, but the strongly and weakly correlated environmental variables will

294 still be distinguished. Local extinctions, extirpation, caused a decline in ecometric

295 correlations; however, up to $75 \%$ of species could be lost this way before ecometric

296 patterns were completely lost. This result suggested that even in fossil faunal

297 assemblages with a small proportion of the total fauna, the ecometric patterns may still be 
298 recoverable if enough independent assemblages are considered. These authors also

299 showed that global extinction and large-scale extirpation have a less predictable effect on

300 ecometric correlations than do local extinctions. How the ecomtetric pattern is affected

301 by global extinciton depends on which organisms go extinct and what their ecometric

302 correlation was. So, if a species, such as a polar bear, is a large contributor to local

303 ecometric means, and if its range is correlated to an extreme of the environmental

304 variable, such as zero vegetation cover, then its extinction could drive correlation up or

305 down dependent on the circumstance.

Ecometric Modeling

307 Polly et al. (2016a) used stochastic modeling to assess the role of population level

308 processes in the formation of ecometric patterns. They systematically varied parameters

309 like local selection intensity, probability of dispersal, probability of extirpation, gene

310 flow, and ancestral trait value to understand the interaction between geographic sorting

311 processes, trait selection, and clade dynamics in producing ecometric patterns. These

312 authors introduced the concept of ecometric load, an analogy with genetic or mutational

313 load, as the mismatch between the distribution of functional traits in a community (or a

314 group of communities) and the selective optimum for those traits in the local environment

315 (Polly et al. 2016a). In cases where ecometric load can be measured, it may help predict

316 whether environmental change is likely to make a community more vulnerable to

317 reorganization or extinction. Interestingly, their models frequently produced parallel trait

318 evolution in different clades, rather than the kinds of phylogenetically correlated trait

319 distributions that are observed in many clades. For example, calcaneum gear ratio, which

320 has strong ecometric sorting in the real world, also has a strong phylogenetic correlation 
321 with about $60 \%$ of its variance being explained by phylogeny (Polly et al. , 2017). The

322 lack of phylogenetic correlation in the models suggested that empirically observed

323 examples of trait-based phylogenetic sorting of species into communities in the modern

324 world results from large-scale turnover in environments.

326 Ecogeographical rules often describe patterns that we would classify as ecometric.

327 Ecogeographic rules are hypotheses about how morphological variation changes along

328 environmental or geographic gradients. They may be rules regarding within-species

329 variation or between-species variation. Across species variation has been the most

330 important component of variation to consider for the ecometric approach.

331 The most notable ecogeographic rule is Bergmann's Rule (Bergmann 1847;

332 Blackburn et al. 1999). It states that body mass correlates with temperature and this has

333 been demonstrated both intraspecifically (Ashton 2002; Freckleton et al. 2003) and

334 interspecifically (Blackburn and Hawkins 2004; Diniz-Filho et al. 2007). Other

335 ecogeographical rules include Allen's rule (length of appendages in endotherms

336 positively correlate with temperature; Allen 1877), Gloger's rule (pigmentation is

337 correlated with humidity within endothermic species; Gloger 1833), Fox's rule (among

338 small Australian mammals during community assembly, it is more likely that species

339 entering a community will represent different functional groups; Fox 1987) and Jordan's

340 rule (there is an inverse relationship between meristic characters and water temperature;

341 Lincoln et al. 1982). See Gaston et al. (2008) for a review of ecogeographic rules. 
345 In order to document the existence of an ecometric pattern, three types of data are

346 required: geographic ranges of species, abiotic conditions, and functional trait

347 measurement of species. The spatial resolution of the data and the density of sampling of

348 traits and environmental variables within local communities will depend on the scale of

349 the functional relationship and on the question being addressed. Here we focus on

350 ecometric patterns that emerge at regional, continental, or global scales, but the same

351 principles could be applied to patterns that emerge on landscape scales. To simplify

352 large-scale analysis, we recommend measuring trait distributions by sampling the trait

353 once for each species making up the local community and making the assumption that

354 each species has the same trait value everywhere it occurs. Finer scale analyses might

355 benefit from sampling the frequencies of traits among the individuals in a local

356 community to account for variation in abundance of the species making up the

357 community, or from measuring the local values of traits within each community. Because

358 of our choice of scale, our analysis requires information about the geographic range

359 where species are known to live or where they have the potential to live. For our

360 purposes, local community composition includes all the species whose ranges overlap at

361 a sampling point, an assumption that is reasonable for coarse scale analysis, but which

362 might be unreasonable for a finer-scale landscape analysis.

\section{Geographic Range}

364 Geographic range data are often available from field guides and are becoming

365 more readily available online as spatial shapefiles. For example, NatureServe

366 (www.natureserve.org) and International Union for Conservation of Nature host a 
367 website that has an option to download spatial data that depict the ranges of species as

368 polygons (www.iucnredlist.org). The ranges are typically drawn by experts and represent

369 the general areas of occupation of a species. Species occurrences may be used to draw

370 range maps, if no range maps are available, so long as the occurrence data are relatively

371 randomly distributed across the entire environmental range of the species. Once the

372 geographic ranges are obtained, a sampling scheme for measuring the trait-environment

373 relationship needs to be determined. Sampling sites may be systematically or randomly

374 scattered across the extent of the study area. A list of species that occur at each sample

375 site should then be compiled. Some sources of data for geographic ranges include the

376 NatureServe and IUCN for mammals, birds, amphibians, coral and some fishes

377 (www.iucnredlist.org). Plant distribution data for North America and Europe are

378 available from USDA PLANTS database (plants.usda.gov) and from the European

379 Environmental Agency (eea.europa.eu). The Global Biodiversity Information Facility

380 contains species occurrences (longitude and latitude) of both plants and animals

381 (www.gbif.org). A geographic information system (GIS) is useful to work with

382 geographic ranges and other geographic information. Open source systems are available,

383 such as QGIS, DIVA, or even R. Proprietary software is also available; the most popular

384 products are developed through ESRI. Researchers should check with their institutions

385 for GIS services and licensing.

387 Environmental factors can be measured directly in the field at sample sites or

388 collected from maps representing the geographic variability of the environmental

389 condition. For every sample site, the environmental variables that are functionally linked 
390 to the trait of interest should be sampled. PRISM Climate Group and WorldClim

391 databases provide relatively high-resolution datasets of climate for the globe

392 (www.prism.oregonstate.edu and www.worldclim.org, respectively). Global potential

393 vegetation is available from UW SAGE (www.washington.edu/research/tools/sage/);

394 global historical vegetation coverage is available from Oak Ridge National Laboratories

395 (dx.doi.org/10.3334/ORNLDAAC/419); global digital elevation models and annual

396 productivity are available from NASA (earthobservatory.nasa.gov/) and USGS

397 (nationalmap.gov/elevation.html); global soil distributions are available from

398 International Institute for Applied Systems Analysis (www.iiasa.ac.at/); global land cover

399 is available from the European Space Agency (www.esa.int/); global nitrogen deposition

400 is available from Oak Ridge National Laboratory (www.ornl.gov); global freeze and thaw

401 status is available from the National Snow and Ice Data Center (nsidc.org/); global

402 terrestrial ecosystems are available from World Wildlife Fund (www.worldwildlife.org).

403 In addition to all of these data sources, there are numerous others to find online and in the

404 published literature. One may use any reliable map as a reference for the environmental

405 condition at sample localities.

\section{Functional Traits}

407 Functional traits should be measured or categorized for each species that has the 408 functional trait of interest within each community. Ideally, one would measure the traits

409 from all the species that occur at each sampling location; however, a species value may

410 be used for all of the locations in which that species occurs. Species values for traits may

411 be collected from measuring specimens directly or from obtaining measures from the

412 published literature. Typically only one value for each species is necessary; however, if 
413 there is strong geographic variation, the analysis can include species values that are

414 geographically explicit. If the functional trait is variable within species to the extent that

415 it causes performance differences, then individuals should be sorted along the

416 environmental gradient, but if that variation does not cause performance differences with

417 respect to the environmental gradient, then it is reasonable to ignore the within species

418 variation. The functional traits may be continuous or categorical in nature.

419 The equipment necessary for collecting the measurements of functional traits

420 greatly varies depending on the trait of interest. One may collect trait data from published

421 literature, and thus, no equipment is necessary. If measurements are taken directly from

422 specimens, the researcher might want to photograph specimens or use calipers to take

423 direct measurements from specimens. If photographs are taken to investigate specimens,

424 the orientation of the camera and the orientation of the specimen should be consistent for

425 all photographs and photos should include a scale. For classifications or counts, no

426 equipment is necessary, unless the researcher requires magnification. For geometric

427 morphometrics, a camera and scale bar, a 3D scanner, or other digitizing equipment is

428 necessary.

\section{Data Analysis}

430 For each sample site, a list of the relevant species that co-occur there must be

431 assembled. The distribution of functional traits in the community members can then be

432 measured. For the remaining examples, we will use the trait mean to summarize that

433 distribution, but other distributional statistics such as variation, standard deviation, range,

434 or median may be appropriate depending on the expected relationship between the trait

435 and its associated environmental parameter. It is useful to assemble data from all 
436 sampling sites into a table with the mean trait values and the associated environmental

437 values in columns and sites in the rows. If there is more than one environmental variable

438 associated with the trait of interest, then in this table each variable requires its own

439 column. Ecometric correlation can easily be calculated from this table as the Pearson's

440 correlation coefficient $(r)$, or a nonparametric equivalent, of the two columns as a

441 measure of correspondence between the environmental parameter and the ecometric trait.

442 If the performance relationship between trait and environment is known, the ecometric

443 load can be calculated as the mean absolute difference between the observed trait means

444 and the expected values for all rows in the table (i.e. the residual between the observed

445 and expected values). Note that ecometric load is largely independent of the ecometric

446 correlation, except insofar that a weak correlation requires at least some mismatch

447 between performance optimum and realized trait mean and thus cannot have a load of

448 zero (Polly et al. 2016a). Ecometric patterns with strong correlations can also have strong

449 loads. Establish a transfer function to determine the specific relationship between the two

450 variables (i.e. it estimates function coefficients). If there are fossil localities to estimate

451 past abiotic conditions, then apply the transfer function to the mean of the functional

452 traits measured from the fossils at a single fossil site. Calculate confidence limits for the

453 estimated abiotic condition.

454 Ecometric estimates of paleoenvironment can be made from a regression-based

455 transfer function or from a likelihood distribution of environmental values given an

456 observed ecometric value. If regression-based methods are used, reduced major axis

457 (RMA) regression may be the most appropriate if there is uncertainty in the independent

458 variable. Transfer functions are prediction equations derived from regressing the 
459 environmental variable of interest onto the predictive trait value. Different transfer

460 functions are used depending on the type of trait variable and the type of environmental

461 variable. Other considerations include the type of predicted relationship between the trait

462 and environment and the statistical fitting procedures.

463 Transfer functions have been typically calibrated with modern distributions of

464 species and their functional traits. For optimal use of the transfer function, for both

465 reconstructing abiotic condition and tracking trait distributions through time, the

466 functional trait should be either directly fossilizable or able to be estimated from fossil

467 specimens. For example, hypsodonty may be estimated directly from fossil specimens

468 (Fortelius et al. 2002) and body size may be accurately estimated from fragmentary

469 skeletal and dental remains (Alexander 1989; MacFadden 1990).

\section{STRENGTHS OF APPROACH}

Ecometrics allows us to quantify the dynamic relationships between organisms

474 and their environment. Arguably, the primary strength is that ecometric traits are

475 predictable and transferable through space and time. Since ecometrics uses taxon-free

476 descriptors of community characteristics, it allows for the comparison of community

477 changes in the modern world to those in deep time (Eronen et al. 2010a; Polly et al.

478 2011). The species that make up the community in the modern world do not need to be

479 the same as those that make up the paleocommunity; the only thing the two communities

480 need to share is the functional trait under study. Because ecometrics focuses on traits that

481 are directly related to environmental conditions, it can be applied to questions on many 
482 geographic and temporal scales (Wolfe 1994; Wether et al. 1999; Thompson et al. 2001;

483 Fortelius et al. 2002). This quality allows ecometrics to be applied at local community

484 levels up to global community levels. It also allows for the comparison of ecometric

485 patterning across these scales. In addition, many ecometric traits are easily measured on

486 both animal and plant fossils (Alexander 1989; MacFadden 1990; Fortelius et al. 2002;

487 Royer et al. 2005; Head et al. 2009).

\section{BIASES AND SHORTCOMINGS}

The incomplete nature of the fossil record may influence the quality of data in

492 ecometric studies. However, Polly and Sarwar (2014) showed that even if only $25 \%$ of

493 the species of a community are found in a fossil locality, the ecometric patterns still

494 appear. Taphonomic issues with the fossil preservation should also be taken into account, 495 because the functional traits used in ecometric studies need to be measurable or inferred

496 from the fossil remains. It has often not been the case where this is an issue (Alexander

497 1989; MacFadden 1990; Fortelius et al. 2002; Royer et al. 2005; Head et al. 2009; Peppe

498 et al. 2011; Wilson et al. 2012) and there are various ways to remove the taphonomic

499 influence from the fossil, thus returning it, or a model of it, to its original state (i.e.,

500 retrodeformation methods; Webster and Hughes 1999; Angielczyk and Sheets 2007).

501 Several important assumptions are made with the ecometric approach, including,

502 that the ecometric relationship doesn't change through time and that the full range of

503 morphologies and environmental conditions are represented (i.e. they are not truncated -

504 there are no biased extinctions and only analogous climate conditions). If these are 
505 reasonable assumptions for the ecometric trait in question, one may use an ecometric

506 relationship to reconstruct paleoclimate and paleoenvironment, given a couple more

507 assumptions about the fossil localities. The community of fossils within the fossil

508 localities being studied should represent the actual community of species that co-occurred

509 with the depositional environment. In addition, the functional traits should be measurable

510 in the preserved fossils. More work is needed to quantify coefficients describing the

511 relationship between functional traits and environmental conditions to understand if and

512 how they change through time and space.

513 More research needs to be done concerning intraspecific variation. Intraspecific

514 variation, at least in regards to carnivoran calcaneum gear ratios, is high, and it does not

515 follow community level ecometric patterning. Models seem to support the idea that this is

516 possible due to the high level of gene flow within populations, but the overall signal at

517 the community level overshadows the intraspecific variation of the populations.

518

519

VII. ECOMETRICS EXAMPLE

520

521 In this section we provide a worked example of how mean annual temperature can

522 be estimated from the distribution of body masses in North American mammals using a

523 likelihood approach. In addition to presenting the method, we also discuss the theory for

524 why ecometric distributions are related to local environment and how our methodology is

525 related to that theory.

526 When the relationship between trait performance and environment is known, the

527 likelihood function can, in theory, be determined a priori (Arnold 1983). Performance- 
528 environment relationships can sometimes be estimated for traits recovered in fossils using

529 tools such as finite element analysis, hydrodynamic or mechanical principles, or

530 functional morphological experimentation (e.g., Baumiller et al. 1991; Rayfield 2007;

531 Wroe 2008; Shino and Suzuki 2011; Stayton 2011; Polly et al. 2016b). However, in

532 many cases the performance-environment relationship is unknown, even when the trait-

533 function relationship is well understood. For example, the functional role of hind-limb

534 gear ratio of mammals is understood (it is related through physical lever principles to the

535 efficiency of hind limb extension, and thus to the mechanics of walking, springing,

536 climbing, and running), but its distribution in a particular environment is difficult to

537 predict a priori because it is likely to be influenced by a combination of factors such as

538 vegetation physiognomy, terrain ruggedness, substrate, snow cover, and predator-prey

539 interactions (Klein et al. 1987; Polly 2008, 2010; Crête and Larivìere 2003). In such

540 cases, likelihoods can be estimated directly from empirical data by making the

541 assumption that the distribution of traits in modern communities is close enough to

542 equilibrium to be representative. Polly and Sarwar (2014) found this to be a reasonable

543 assumption for carnivore limb ratios, but care should be taken before generalizing that

544 result to other traits.

545

546

[insert Figure 2 near here]

547

548 Likelihoods for paleoenvironmental parameters can be estimated empirically by

549 projecting environmental variables into an ecometric space, which is a mathematical

550 space whose axes are statistical descriptors of the distribution of traits in local 
551 communities (Figure 2A). Ecometric space is in some ways the conceptual opposite of

552 Hutchinson's (1957) niche space, in which a species' niche is the volume it occupies in a

553 multidimensional space whose axes are environmental variables. Translated into

554 ecometric terms, the niche of a species is circumscribed by the performance of the

555 functional traits that relate it to the environmental factors. An ecometric space inverts that

556 relationship by mapping the distribution of environmental parameters on trait-based axes,

557 except that those axes describe the distribution of traits in community assemblages rather

558 than the traits of a single species. Figure 2A shows mean annual temperature mapped

559 into an ecometric space whose axes are defined by the distribution of log body mass $(\mathrm{kg})$

560 of mammals.

561 To create this ecometric space we sampled mammal faunas at $50 \mathrm{~km}$ intervals

562 across the entirety of North America. At each sampling point we calculated the mean and

563 standard deviation of the body masses $(\mathrm{kg})$ of the local mammals from the data compiled

564 by Smith et al. (2003) and we recorded the local mean annual temperature (MAT) from

565 Hijmans et al. (2005).

566 Estimating the likelihood of MAT from community trait characteristics is then a

567 three-step process. First, the trait data should be binned so that a frequency distribution of

568 the environmental variable can be calculated. The number of bins is arbitrary, but it

569 should be coarse enough to encompass a reasonable number of communities in the

570 densest areas of the trait space, yet fine enough to be biologically meaningful. The ideal

571 bin size would be about as wide as the standard errors of the means and standard

572 deviations in the bin. We divided our ecometric space into 625 bins ( 25 X 25). 
574 tabulate their frequency distribution. The number of temperature bins is also arbitrary (we

575 used a bin size of $1^{\circ} \mathrm{C}$ ). Once binned, a discrete probability density function (PDF) can be

576 estimated by dividing the bin counts by the total number of observations. A continuous

577 PDF can also be fit to the frequency data. Figure 2B shows a continuous PDF for

578 temperature in communities with a mean $\ln$ body mass between $3.05(21.11 \mathrm{~kg})$ and 3.13

$579(22.87 \mathrm{~kg})$ and a standard deviation between 1.05 and 1.10 (black box in Figure 2A)

580 based on a Gaussian kernel density estimate with bandwidth of $1{ }^{\circ} \mathrm{C}$.

581 With these pieces in place, a maximum likelihood estimate of the environmental variable

582 (MAT) can be made by measuring the trait (body mass) mean and standard deviation at a

583 site of interest and then finding the environmental value that maximizes the PDF. The

584 maximum likelihood estimates of MAT for all the sampling locations in North America

585 are shown in Figure 2C, compared with the real MAT values in Figure 2D. This

586 estimate (MAT at sampling locations) is reasonable, but tends to be too low in high

587 elevation areas and too warm at lower elevations (see anomaly map in Figure 2E). On

588 average, the discrepancy between the real MAT and the estimate based on mammal body

589 masses was $3.9^{\circ} \mathrm{C}$, which serves as an approximate standard error (but one that is

590 probably underestimated because the likelihood functions were estimated from the same

591 data on which they were tested).

592 One of the primary advantages of using likelihood and ecometric spaces is that the

593 likelihoods of alternative reconstructions can be compared. For example, the maximum

594 likelihood estimate of MAT for the Central American location highlighted by the black

595 circles in Figure 2C-E is $24.95^{\circ} \mathrm{C}$ with $L(24.95)=0.274$ derived from the PDF for that 
596 location (Figure 2B). The real MAT is $25.3^{\circ} \mathrm{C}$, which has $L(25.3)=0.265$, which is

597 clearly much more plausible with a likelihood ratio of 0.967 than an MAT of $20^{\circ} \mathrm{C}$,

598 where $L(20.0)=0.024$ produces a likelihood ratio of only 0.088 . This approach can be

599 developed into a formal likelihood ratio test of alternative hypotheses about

600 paleoenvironment, and it can be combined with prior probabilities from independent

601 paleoenvironmental proxies into a Bayesian framework (Polly and Head 2015).

602 The second advantage of the likelihood approach is that incommensurable traits can be

603 combined. Mammalian body mass distributions were fairly good predictors of MAT, as

604 might be expected by extrapolating Bergmann's rule, which postulates that subspecies in

605 colder climates will have larger body mass than their conspecifics elsewhere (Bergmann

606 1947; Scholander 1955; Mayr 1963), to the level of species and communities. However,

607 homeothermic mammals are well-insulated from climate and their body size may not be

608 as good predictors of MAT as that of ectotherms (Head et al. 2009). Because large

609 ectothermic animals require warm ambient temperatures to sustain their growth rate, the

610 size range of species in hot climates is expected to be greater than in cold climates

611 (Makarieva et al. 2005). Using a dataset of ventral scale count as a proxy for size

612 assembled by Lawing et al. (2012), we repeated the likelihood estimation for MAT in

613 North America using the range of log scale count and its standard deviation as the

614 dimensions of the ecometric space (Figure 2F). These two parameters are both measures

615 of dispersion and are therefore correlated, yet pick out different aspects of the distribution

616 of body size in local communities. These data yield a similar likelihood function for the

617 site in Central America, but with a narrower peak of predicted MAT (Figure 2G).

618 Because the likelihood functions are probabilities, they can be combined by multiplying 
619 them and renormalizing so that the area under them is 1.0. The resulting function gives

620 the likelihood of MAT given the distribution of body masses in mammals and the

621 distribution of ventral scale counts in snakes. This combined likelihood function provides

622 a better estimate of temperature than either trait does alone (Figure 2H-J). The mean

623 anomaly between estimated and real temperature based on the combined estimate is only

$6242.4^{\circ} \mathrm{C}$, much better than with mammals alone. Sacrificed is the ability to estimate MAT in

625 the northern part of the continent where the climate is too cold for snakes to live.

626 A fully worked ecometrics example and R code is documented in Appendix I.

627

\section{FUTURE PROSPECTS}

629

630 Several aspects of ecometrics need to be addressed with future research. These

631 areas include - intraspecific variation, abundance, phylogenetics, combining multiple

632 ecometrics, conservation, and ecosystem services. Polly et al. (2016a) took first steps to

633 identify and define a theory of ecogeography- moving from pattern to process with

634 ecometric modeling. They used modeling to simulate the affects of changing

635 microevolutionary processes on the ecometric patterning seen at the community level. As

636 this area of interest progresses, eventually we hope to be able to observe ecometric

637 patterns and determine which microevolutionary and macroevolutionary processes caused

638 the patterns we see. One area of ecometric study that deserves further study is the affects

639 of intraspecific variation in ecometric patterns. Polly et al. (per comm) show that while

640 intraspecific variation, at least in regards to carnivoran calcaneum gear ratios, is high, it

641 does not follow community level ecometric patterning. Models seem to support the idea 
642 that this is possible due to the high level of gene flow within populations, but the overall

643 signal at the community level overshadows the intraspecific variation of the populations.

644 Another future development in the field of ecometrics is the prospect of marine

645 ecometrics (Wallin 1991; Yasuhara et al. 2015). Due to the depositional environments

646 found in marine systems, marine fossils are the majority of fossils found (Sepkoski

647 1978). Marine fossils are often used in isotopic studies to reconstruct paleoecology

648 (Bowen 1964; Anderson and Arthur 1983; Krantz et al. 1987; Wefer and Berger 1991;

649 Rodrigues et al. 2014; Huyghe et al. 2015; Reich et al. 2015). The changes in isotopic

650 fractionation may follow geographical gradients similar to an ecometric (Marchais et al.

651 2013; Lynch-Stieglitz et al. 2015; Mackenzie et al. 2014; Beard et al. 2015). However,

652 the isotopic fractionation process is not a morophological trait, it is a metabolic functional

653 trait, and as such, follows different biological, physical, and chemical rules.

654 New advances in remote sensing capabilities could alter the accuracy of our

655 estimates of both species geographic ranges and the environmental condition in which

656 they occur. Remote sensing appears like it will be quite useful when studying changes in

657 plant community structures over large geographic regions. It allows for a level of detail in

658 which single plants are recognizable across regional scales (Jones and Vaughan 2010).

659 Geometric morphometrics will also allow for the study of ecometrics when a

660 particular functional trait changes size across age, but doesn't change shape (or vice

661 versa). New advances will also allow for 3D modeling of functional traits. This may

662 allow for the identification of aspects of the morphology that are better ecometrics than

663 those being used. It can also allow for better ecometrics since we will no longer be using

664 linear or volumetric measurements, but instead use the full 3D shape. Recent work by 
665 Polly (2010) and Wilson et al. (2012) has shown that this is a viable avenue of future

666 inquiry.

667

668

\section{REFERENCES}

669

670 Alexander, R. M. (1989). Optimization and gaits in the locomotion of vertebrates.

671 Physiological Reviews, 69, 1199-1227.

672 Anderson, T.F. \& Arthur, M. A. (1983). Stable isotopes of oxygen and carbon and 673 their application to sedimentologic and paleoenvironmental problems. In M.

674

675

A. Arthur, T. F. Anderson, I. R. Kaplan, J. Veizer, \& L. S. Land (Eds.),

Stable Isotopes in Sedimentary Geology (pp. 1 - 151), Tulsa, OK: SEPM Short

676 Course.

677 Andrews, P. \& Hixson, S. (2014). Taxon-free methods of palaeoecology. Annales Zoologici Fennici, 51, 269-284.

679 Angielczyk, K.D. \& Sheets, H.D. (2007). Investigation of simulated tectonic

680 deformation in fossils using geometric morphometrics. Paleobiology, 33, 125-

$681+148$.

682 Arnold, S. J. (1983). Morphology, performance and fitness. American Zoologist, 23, 683 347-361.

684 Ashton, K. G. (2002). Do amphibians follow Bergmann's rule? Canadian Journal of 685 Zoology, 80, 708-716.

686 Bailey, I. W. \& Sinnott, E. W. (1915). A botanical index of Cretaceous and Tertiary

687 climates. Science, $41,831-834$. 
688 Barnosky, A. D., E. A. Hadly, P. Gonzalez, J. J. Head, P. D. Polly, A. M. Lawing, J.

689 T. Eronen, D. D. Ackerly, K. Alex, E. Biber, J. Blois, J. Brashares, G.

690 Ceballos, E. Davis, G. P. Dietl, R. Dirzo, H. Doremus, M. Fortelius, H. W.

691 Greene, J. Hellmann, T. Hickler, S. T. Jackson, M. Kemp, P. L. Koch, C.

692 Kremen, E. L. Lindsey, C. Looy, C. R. Marshall, C. Mendenhall, A.S Mulch,

693 A. M. Mychajliw, C. Nowak, U. Ramakrishnan, J. Schnitzler, K. D. Shrestha,

694 K. Solari, L. Stegner, M. A. Stegner, N. Chr. Stenseth, M. H. Wake. Z. Zhang.

695 2017. Merging paleobiology with conservation biology to guide the future of 696 terrestrial ecosystems. Science, 355 (6325). doi: 10.1126/science.aah4787

697 Baumiller, T. K., LaBarbera, M. \& Woodley, J. D. (1991). Ecology and functional

698 morphology of the isocrinid Cenocrinus asterius (Linnaeus) (Echinodermata:

699 Crinoidea): in situ and laboratory experiments and observations. Bulletin of

$700 \quad$ Marine Science, 48, 731-748.

701 Beard, J. A., Ivany, L. C. \& Runnegar, B. (2015). Gradients in seasonality and

702 seawater oxygen isotopic composition along the early Permian Gondwanan

703 coast, SE Australia: Earth and Planetary Science Letters, 425, 219-231.

704 Beerling, D., Lomax, B., Royer, D., Upchurch, G. \& Kump, L. (2002). An

705 atmospheric $\mathrm{pCO} 2$ reconstruction across the Cretaceous-Tertiary boundary

706 from leaf megafossils. Proceedings of the National Academy of Sciences of

$707 \quad$ the United States of America, 99, 7836-7840.

708 Beerling, D. J., Fox, A., Stevenson, D. S. \& Valdes, P. J. (2011). Enhanced

709 chemistry-climate feedbacks in past greenhouse worlds. Proceedings of the

$710 \quad$ National Academy of Sciences, 108, 9770-9775. 
711 Belmaker, J. \& Jetz, W. (2012). Regional pools and environmental controls of

712 vertebrate assemblages. American Naturalist, 179, 512-523.

713 Bergmann, C. (1847). Ueber die Verhältnisse der Wärmeökonomie der Thiere zu

714 ihrer Grösse. Gottinger studien, 3, 595-708.

715 Blackburn, T. M., Gaston, K. J. \& Loder, N. (1999). Geographic gradients in body

716 size: a clarification of Bergmann's rule. Diversity and Distributions, 5, 165-

$717+174$.

718 Blackburn, T. M. \& Hawkins, B. A. (2004). Bergmann's rule and the mammal fauna

719 of northern North America. Ecography, 27, 715-724.

720 Bowen, R. (1964). Oxygen isotope paleotemperature measurements on Mesozoic

721 Belemnoidea and their importance in paleoclimatic studies. In U. Colombo \&

722 G. D. Hobson (Eds.) Advances in organic Geochemistry (pp. 271-283). New

723 York, NY: Pergamon.

724 Chapin, F. S. III. (1993). Functional role of growth forms in ecosystem and global

725 processes. In J. R. Ehleringer \& C. B. Field (Eds.) Scaling Physiological

726 Processes: Leaf to Globe (pp. 287-312). San Diego, CA: Academic Press.

727 Cornwell, W. K. \& Ackerly, D. D. (2009). Community assembly and shifts in plant

728 trait distributions across an environmental gradient in coastal California.

729 Ecological Monographs, 79, 109-126.

730 Crête, M. \& Lariviere, S. (2003). Estimating the costs of locomotion in snow for

731 coyotes. Canadian Journal of Zoology, 81, 1808-1814.

732 Damuth, J. D., Jablonski, D., Harris, R. M., Potts, R., Stucky, R. K., Sues, H. D. \&

733 Weishampel, D. B. (1992). Taxon-free characterization of animal 
communities. In A. K. Beherensmeyer, J. D. Damuth, W. A. diMichele, R. Potts, H. D. Sues, \& S. L. Wing (Eds.) Terrestrial Ecosystems Through Time: Evolutionary Paleoecology of Terrestrial Plants and Animals (pp. 183-203). Chicago: University of Chicago Press.

738 Damuth, J. D. \& Janis, C. M. (2011). On the relationship between hyposodonty and feeding ecology in ungulate mammals and its utility in paleaeoecology.

741 Darwin, C. R. \& Wallace, A. R. (1858). On the tendency of species to form varieties; and on the perpetuation of varieties and species by natural means of selection. Journal of the Proceedings of the Linnean Society of London. Zoology, 3, 4550.

745 Díaz, S. \& Cabido, M. (2001). Vive la différence: plant functional diversity matters to ecosystem processes. Trends in Ecology \& Evolution, 16, 646-655.

747 Diniz-Filho, J.A.F., Bini, L. M., Rodriguez, M. A., Rangel, T. F. L. \& Hawkins, B. A. 748 (2007). Seeing the forest for the trees: partitioning ecological and 749 phylogenetic components of Bergmann's rule in European Carnivora. $750 \quad$ Ecography, 30, 598-608.

751 Eronen, J. T., Polly, P. D., Fred, M., Damuth, J., Frank, D. C., Mosbrugger, V., 752 Scheidegger, C., Stenseth, N. C. \& Fortelius, M. (2010a). Ecometrics: the

754 Eronen, J., Puolamaki, K., Liu, L., Lintulaakso, K., Damuth, J., Janis, C. \& Fortelius, 755 M. (2010b). Precipitation and large herbivorous mammals I: estimates from 756 present-day communities. Evolutionary Ecology Research, 12, 217-233. 
757 Eronen, J. T., Fortelius, M., Micheels, A., Portmann, F. T., Puolamäki, K. \& Janis, C. M. (2012). Neogene Aridification of the Northern Hemisphere. Geology, 40, $823-826$.

760 Evans, A. R. (2013). Shape descriptors as ecometrics in dental ecology. Hystrix, the Italian Journal of Mammalogy, 24, 133-140.

762 Fortelius, M., Eronen, J. T., Jernvall, J., Liu, L. P., Pushkina, D., Rinne, J., Tesakov, 763 A. et al. (2002). Fossil mammals resolve regional patterns of Eurasian climate change over 20 million years. Evolutionary Ecology Research, 4, 1005-1016.

765 Fortelius, M., Eronen, J. T., Kaya, F., Tang, H., Raia, P. \& Puolamäki, K. (2014).

766 Evolution of Neogene mammals in Eurasia: environmental forcing and biotic 767 interactions. Annual Review of Earth and Planetary Sciences, 42, 579-604.

768 Fox, B. J. (1987). Species assembly and the evolution of community structure.

769 Evolutionary Ecology, 1, 201-213.

770 Freckleton, R. P., Harvey, P. H. \& Pagel, M. (2003). Bergmann's rule and body size 771 in mammals. The American Naturalist, 161, 821-825.

772 Gaston, K.J., Chown, S.L. \& Evans, K.L. (2008). Ecogeographical rules: elements of 773 a synthesis. Journal of Biogeography, 35, 483-500.

774 Head, J. J., Bloch, J. I., Hastings, A. K., Bourque, J. R., Cadena, E. A., Herrera, F. A., 775 Polly, P.D. \& Jaramillo, C. A. (2009). Giant boid snake from the Palaeocene 776 neotropics reveals hotter past equatorial temperatures. Nature, 457, 715-717.

777 Head, J. J., G. F. Gunnell, P. A. Holroyd, J. H. Hutchison, \& R. L. Ciochon. (2013). 778 Giant lizards occupied herbivorous mammalian ecospace during the 
Paleogene greenhouse in Southeast Asia. Proceedings of the Royal Society of

$780 \quad$ London, Series B., 280, 20130665.

781 Hijmans, R. J., Cameron, J. L., Parra, P. G., Jones, P. G. \& Jarvis, A. (2005). Very

782 high resolution interpolated climate surfaces for global land areas.

783 International Journal of Climatology, 25, 1965-1978.

784 Huyghe, D., Lartaud, F., Emmanuel, L., Merle, D. \& Renard, M. (2015). Palaeogene

785 climate evolution in the Paris Basin from oxygen stable isotope $(\delta 180)$

786 compositions of marine molluscs. Journal of the Geological Society, 172,

$787 \quad 576-587$.

788 Jackson, S. T. \& Overpeck, J. T. (2000). Responses of plant populations and

789 communities to environmental changes of the late Quaternary.

$790 \quad$ Paleobiology, 26, 194-220.

791 Janis, C. M. \& Fortelius, M. (1988). On the means whereby mammals achieve

792 increased functional durability of their dentitions, with special reference to

793 limiting factors. Biological Reviews of the Cambridge Philosophical Society,

$794 \quad 63,197-230$.

795 Jones, H. G. \& Vaughan, R. A. (2010). Remote sensing of vegetation: principles,

796 techniques, and applications. New York, NY: Oxford University Press.

797 Klein, D. R., Meldgaard, M. \& Fancy, S. G. (1987). Factors determining leg length in

798 Rangifer tarandus. Journal of Mammalogy, 68, 642-655.

799 Krantz, D. E., Williams, D. F. \& Jones, D. S. (1987). Ecological and

800 paleoenvironmental information using stable isotope profiles from living and 
fossil molluscs. Palaeogeography, Palaeoclimatology, Palaeoecology, 58, 249-266.

803 Lawing, A. M., Eronen, J. T., Blois, J. L., Graham, C. H. \& Polly, P. D. (2016).

804 Community functional trait composition at the continental scale: the effects of 805 non-ecological processes. Ecography, EarlyView DOI: 10.1111/ecog.01986

806 Lawing, A. M., Head, J. J. \& Polly, P. D. (2012). The ecology of morphology: the 807 ecometrics of locomotion and macroenvironment in North American snakes.

808 In J. Louys (Eds). Paleontology in Ecology and Conservation (pp. 117-146).

809 Berlin: Springer Berlin Heidelberg.

810 Lincoln, R. J. B. \& Clark, G. A. (1982). A dictionary of ecology, evolution and 811 systematics. Cambridge, UK: Cambridge University Press.

812 Little, S. A., Kembel, S. W. \& Wilf, P. (2010). Paleotemperature Proxies from Leaf 813 Fossils Reinterpreted in Light of Evolutionary History. PLoS One, 5, e15161. 814 Liu, L., Puolamäki, K., Eronen, J.T., Ataabadi, M.M., Hernesniemi, E. \& Fortelius, 815 M., 2012. Dental functional traits of mammals resolve productivity in 816 terrestrial ecosystems past and present. Proceedings of the Royal Society of $817 \quad$ London B: Biological Sciences, 20120211.

818 Lynch-Stieglitz, J., Polissar, P. J., Jacobel, A. W., Hovan, S. A., Pockalny, R. A., 819 Lyle, M., Murray, R. W., Ravelo, A. C., Bova, S. C., Dunlea, A. G., Ford, H. 820 L., Hertzberg, J. E., Wertman, C. A., Maloney, A. E., Shackford, J. K., 821 Wejnert, K. \& Xie, R. C. (2015). Glacial-interglacial changes in central 822 tropical Pacific surface seawater property gradients: Paleoceanography, 30, $823 \quad 423-438$. 
824 MacFadden, B. J. (1990). Body size in mammalian paleobiology: estimation and biological implications. Cambridge, UK: Cambridge University Press.

826 Makarieva, A. M., Gorshkov, V. G. \& Li, B. L. (2005). Temperature-associated upper 827 limits to body size in terrestrial poikilotherms. Oikos, 111, 425-436.

828 MacKenzie, K. M., Longmore, C., Preece, C., Lucas, C. H., \& Trueman, C. N.

829 (2014). Testing the long-term stability of marine isoscapes in shelf seas using $830 \quad$ jellyfish tissues. Biogeochemistry, 121, 441-454.

831 Marchais, V., Schaal, G., Grall, J., Lorrain, A., Nerot, C., Richard, P. \& Chauvaud, L. 832 (2013). Spatial Variability of Stable Isotope Ratios in Oysters (Crassostrea 833 gigas) and Primary Producers Along an Estuarine Gradient (Bay of Brest, $834 \quad$ France). Estuaries and Coasts, 36, 808-819.

835 Mayr, E. (1963). Animal Species and Evolution. Cambridge, Massachusetts: Belknap 836 Press of Harvard University Press.

837 Mendoza, M., Janis, C. M. \& Palmqvist, P. 2005. Ecological patterns in the trophic838 size structure of large mammal communities: a 'taxon-free' characterization. 839 Evolutionary Ecology Research, 7, 505-530.

840 Owen-Smith, R. N. (2002). Adaptive herbivore ecology: from resources to 841 populations in variable environments. Cambridge University Press.

842 Peppe, D. J., Royer, D. L., Cariglino, B., Oliver, S. Y., Newman, S., Leight, E., 843 Enikolopov, G., Fernandez- Burgos, M., Herrera, F., Adams, J. M. \& Correa, 844 E. (2011). Sensitivity of leaf size and shape to climate: global patterns and 845 paleoclimatic applications. New Phytologist, 190, pp.724-739. 
846 Poff, N. L. (1997). Landscape filters and species traits: towards mechanistic

847 understanding and prediction in stream ecology. Journal of the North

848 American Benthological Society, 16, 391-409.

849 Polly, P. D. (2008). Adaptive Zones and the Pinniped Ankle: A 3D Quantitative

850 Analysis of Carnivoran Tarsal Evolution. In E. Sargis \& M. Dagosto (Eds.),

851 Mammalian Evolutionary Morphology: A Tribute to Frederick S. Szalay (pp.

852 165-194). Dordrecht, The Netherlands: Springer.

853 Polly, P. D. (2010). Tiptoeing through the trophics: geographic variation in

854 carnivoran locomotor ecomorphology in relation to environment. In A.

855 Goswami \& A. Friscia (Eds.), Carnivoran evolution: new views on phylogeny,

856 form, and function (pp. 347-410). Cambridge, UK: Cambridge University

857 Press.

858 Polly, P. D., Eronen, J. T., Fred, M., Dietl, G. P., Mosbrugger, V., Scheidegger, C.,

859 Frank, D. C., Damuth, J., Stenseth, N. C. \& Fortelius, M. (2011). History

860 matters: ecometrics and integrative climate change biology. Proceedings of

861 the Royal Society of London B: Biological Sciences, rspb20102233.

862 Polly, P. D. \& Head, J. J. (2015). Measuring Earth-life transitions: ecometric analysis

863 of functional traits from late Cenozoic vertebrates. In P. D. Polly, J. J. Head,

864 \& D. L. Fox (Eds.), Earth-Life Transitions: Paleobiology in the Context of

865 Earth System Evolution (pp. 21-46). The Paleontological Society Papers 21.

866 New Haven, CT: Yale Press. 
867 Polly, P. D \& Sarwar, S. (2014). Extinction, extirpation, and exotics: effects on the 868 correlation between traits and environment at the continental level. Annales Zoologici Fennici, 51, 209-226.

870 Polly, P. D., Lawing, A. M., Eronen, J. T. \& Schnitzler, J. (2016a). Processes of 871 ecometric patterning: modeling functional traits, environments, and clade dynamics in deep time. Biological Journal of the Linnaean Society, 118, 3963.

874 Polly, P. D., Stayton, C. T., Dumont, E. R., Pierce, S. E., Rayfield, E. J. \& 875 Angielczyk, K. (2016b). Combining geometric morphometrics and finite element analysis with evolutionary modeling: towards a synthesis. Journal of Vertebrate Paleontology, e1111225, 1-29.

878 Polly, P. D., Fuentes-Gonzales, J., Lawing, A. M., Bormet, A. K., \& Dundas, R. G. 2017. Clade sorting has a greater effect than local adaptation on ecometric 880 patterns in Carnivora. Evolutionary Ecology Research, 18, 187-200.Rayfield, E. J. (2007). Finite element analysis and understanding the biomechanics and evolution of living and fossil organisms. Annual Review of Earth and

884 Reich, P. B., Walters, M. B. \& Ellsworth, D. S. (1997). From tropics to tundra: global 885 convergence in plant functioning. Proceedings of the National Academy of $886 \quad$ Sciences USA, 94, 13730-13734.

887 Reich, S., Warter, V., Wesselingh, F. P., Zwaan, J. C., Lourens, L. \& Renema, W. 888 (2015). Paleoecological significance of stable isotope ratios in Miocene 889 tropical shallow marine habitats (Indonesia): Palaios, 30, 53-65. 
890 Ricklefs, R. E. \& Travis, J. (1980). A morphological approach to the study of Avian community organization. The Auk, 97, 321-338.

892 Rodrigues, G. B., Fauth, G., Santos, R. V., Koutsoukos, E. A. M. \& Colin, J.-P., 893 (2014). Tracking paleoecological and isotopic changes through the K-Pg 894 boundary from marine ostracodes: The Poty quarry section, northeastern 895 Brazil. Cretaceous Research, 47, 105-116.

896 Rodríguez, M.Á., Olalla- Tárraga, M.Á. \& Hawkins, B.A. (2008). Bergmann's rule 897 and the geography of mammal body size in the Western Hemisphere. Global 898 Ecology and Biogeography, 17, 274-283.

899 Royer, D.L. \& Wilf, P. 2006. Why do toothed leaves correlate with cold climates?

900 Gas exchange at leaf margins provides new insights into a classic 901 paleotemperature proxy. International Journal of Plant Science, 167, 11-18.

902 Royer, D.L., Wilf, P., Janesko, D. A., Kowalski, E. A. \& Dilcher, D. L. (2005).

903 Correlations of climate and plant ecology to leaf size and shape: potential

904 proxies for the fossil record. American Journal of Botany, 92, 1141-1151.

905 Saarinen, J. (2014). Ecometrics of large herbivorous land mammals in relation to 906 climatic and environmental changes during the Pleistocene. Department of 907 Geosciences and Geography. Uppsala, Sweden: Uppsala University 908 Dissertation.

909 Saarinen, J. \& Karme, A. (2017). Tooth wear and diets of extant and fossil 910 xenarthrans (Mammalia, Xenarthra)-Applying a new mesowear approach. 911 Palaeogeography, Palaeoclimatology, Palaeoecology, 476, 42-54. 
912 Scholander, P. F. (1955). Evolution of climatic adaptation in homeotherms. Evolution, $913 \quad 9,15-26$.

914 Sepkoski, J.J. (1978). A kinetic model of Phanerozoic taxonomic diversity I. Analysis 915 of marine orders. Paleobiology, 4, 223-251.

916 Shino, Y. \& Suzuki, Y. (2011). The ideal hydrodynamic form of the concavo-convex 917 productide brachiopod shell. Lethaia, 44, 329-343.

918 Smith, F. A., Lyons, S. K., Ernest, S. K. M., Jones, K. E., Kauffman, D. M., Dayan, 919 T., Marquet, P. A., Brown, J. H. \& Haskell, J. P. (2003). Body mass of late 920 Quaternary mammals. Ecology, 84, 3403.

921 Stayton, C. T. (2011). Biomechanics on the half shell: functional performance 922 influences patterns of morphological variation in the emydid turtle carapace. 923 Zoology, 114, 213-223.

924 Strömberg, C. A. E., Dunn, R. E., Madden, R. H., Kohn, M. J. \& Carlini, A. A.

925 (2013). Decoupling the spread of grasslands from the evolution of grazer-type 926 herbivores in South America. Nature Communications, 4, 1478.

927 Tapaltsyan, V., Eronen, J.T., Lawing, A.M., Sharir, A., Janis, C., Jernvall, J. \& Klein, 928 O.D. (2015). Continuously growing rodent molars result from a predictable 929 quantitative evolutionary change over 50 million years. Cell reports, 11, 673$930 \quad 680$.

931 Violle, C., Navas, M. L., Vile, D., Kazakou, E., Fortunel, C., Hummel, I. \& Garnier, 932 E. (2007). Let the concept of trait be functional! Oikos, 116, 882-892. 
933 Wallin, M. (1991). Ecometric analysis of factors regulating eutrophication effects in 934 coastal waters: a case study of marine fish farms. Disciplinary Domain of 935 Science and Technology. Uppsala, Sweden: Uppsala University Dissertation.

936 Webster, M. \& Hughes, N.C. (1999). Compaction-related deformation in Cambrian 937 olenelloid trilobites and its implications for fossil morphometry. Journal of $938 \quad$ Paleontology, 73, 355-371.

939 Wefer, G. \& Berger, W. H. (1991). Isotope paleontology: growth and composition of 940 extant calcareous specie. Marine Geology, 100, 207-248.

941 Wilf, P. (1997). When are leaves good thermometers? A new case for leaf margin 942 analysis. Paleobiology, 23, 373-390.

943 Wilson, G. P., Evans, A. R., Corfe, I. J., Smits, P. D., Fortelius, M. \& Jernvall, J. 944 (2012). Adaptive radiation of multituberculate mammals before the extinction 945 of dinosaurs. Nature, 483, 457-460.

946 Wing, S. L., Harrington, G. L., Smith, F. A., Bloch, J. I., Boyer, D. M. \& Freeman, K.

947 H. (2005). Transient floral change and rapid global warming at the

948 Paleoeocene-Eocene boundary. Science, 310, 993-996.

949 Wolfe, J. A. (1979). Temperature parameters of humid to mesic forests of eastern 950 Asia and relation to forests of other regions of the northern hemisphere and 951 Australasia. Geological Survey Professional Paper, 1106.

952 - (1993). A method of obtaining climatic parameters from leaf assemblages.

953 Bulletin of the US Geological Survey, 2040.

954 - (1994). Tertiary climatic changes at middle latitudes of western North America.

955 Palaeogeography, Palaeoclimatology, Palaeoecology, 108, 195-205. 
956 Wright, I. J., Reich, P. B., Westoby, M., Ackerly, D. D., Baruch, Z., Bongers, F.,

957 Cavender-Bares, J., et al. (2004). The worldwide leaf economics spectrum.

$958 \quad$ Nature, $428,821-827$.

959 Wroe, S. (2008). Cranial mechanics compared in extinct marsupial and extant African

960 lions using a finite-element approach. Journal of Zoology, 274, 332-339.

961 Yasuhara, M., Tittensor, D. P., Hillebrand, H. \& Worm, B. (2015). Combining marine

962 macroecology and palaeoecology in understanding biodiversity: microfossils

963 as a model. Biological Reviews, doi: 10.1111/brv.12223

964 Žliobaitè, I., Rinne, J., Tóth, A.B., Mechenich, M., Liu, L., Behrensmeyer, A.K. \&

965 Fortelius, M. 2016. Herbivore teeth predict climatic limits in Kenyan

966 ecosystems. Proceedings of the National Academy of Sciences, 201609409. 
967 Figure 1. A. Example of an entire leaf margin from a live oak leaf modified from an

968 image by Jeremy Stovall. The leaf margin is entire when its margin is not punctuated. An

969 easy way to determine if the margin is entire or to quantify the entirety of the margin is to

970 overlay the image of the leaf with an oval, as is depicted in the figure with the red outline.

971 Entire leaf margins are characteristic of hotter environments. B. Example of a non-entire

972 leaf margin from a dwarf birch modified from an image by Fox Valley. Non-entire leaf

973 margins are characteristic of cooler environments. C. Example of hypsodonty in a rodent

974 modified by Tapaltsyan et al. 2015. Hypsodonty is measured by the crown to root ratio.

975 Hypsodonts are grazers and are characteristic of arid environments with more gritty

976 vegetation. D. Example of brachydonty in a rodent modified from Tapaltsyan et al. 2015.

977 Brachydonts are browsers and are found in more wet environments with mixed

978 vegetation. E. Example of a calcaneum from a raccoon modified from an image on

979 boneid.net. Gear ratio is measured on the calcaneum and is the ratio of the length of the

980 sustentacular facet to the total length of the calcaneum. The gear ratio for the raccoon is

981 typical of a plantigrade animal and is characteristic for animals living in high vegetation

982 cover (e.g., dense woodlands). F. Example of a calcaneum from a panther modified from

983 an image on boneid.net. The gear ratio in the panther is typical of a digitigrade animal

984 and is characteristic of animals that are adapted to run through open habitats.

986 Figure 2. A. Ecometric space for community-level mammalian body mass showing the

987 maximum likelihood estimation of mean annual temperature (MAT) for each bin. B.

988 Likelihood function for MAT based on mammal body mass at the point in Central

989 America highlighted by the black circles in C-E. C. MAT estimated from mammalian 
990 body mass. D. Observed MAT. E. anomaly between estimated and observed MAT. F.

991 Ecometric space for snake body size showing the maximum likelihood estimate for MAT

992 in each bin. G. Likelihood function for MAT at the same point in Central America based

993 on snake size. H. MAT estimated from combined mammalian body mass and snake size.

994 I. Observed MAT. E. Anomaly between combined estimate and observed MAT.

995

996 

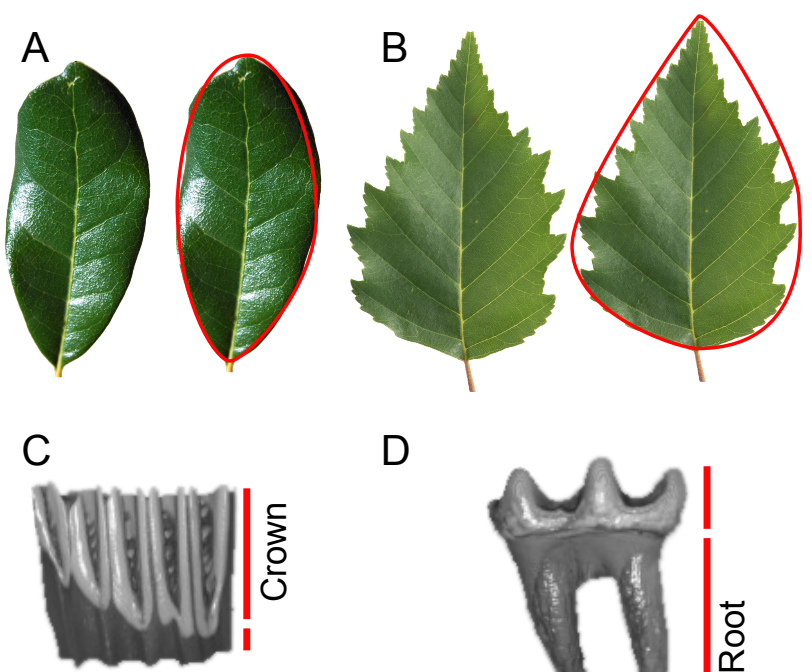

D
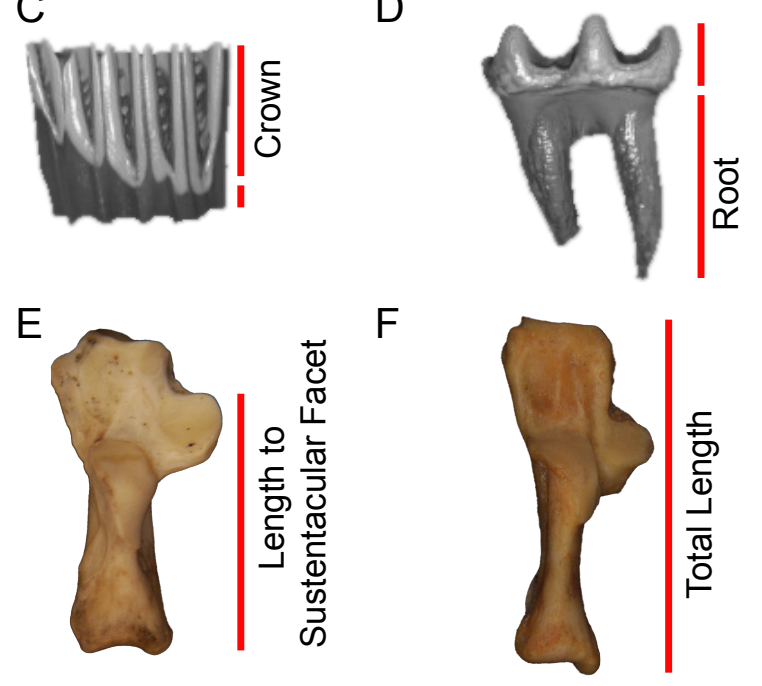

998

999 
Figure 2
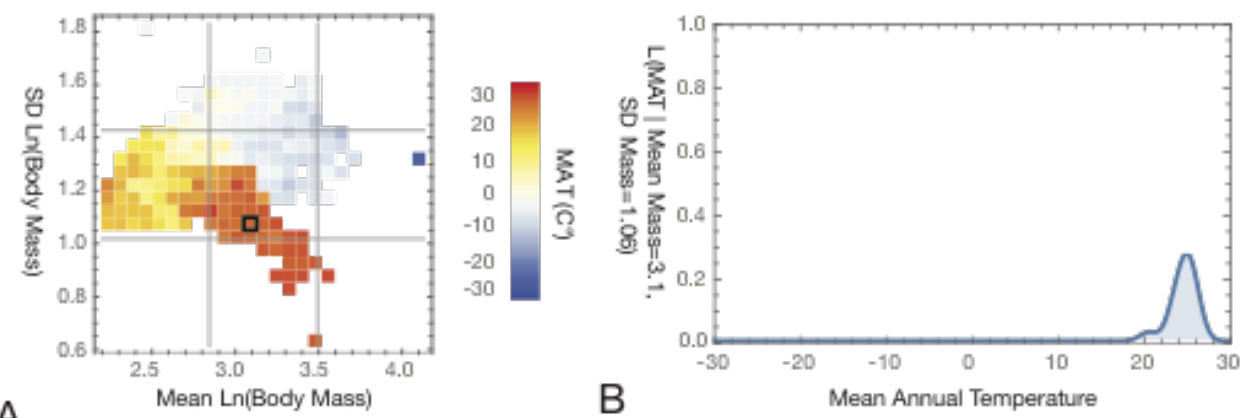

A
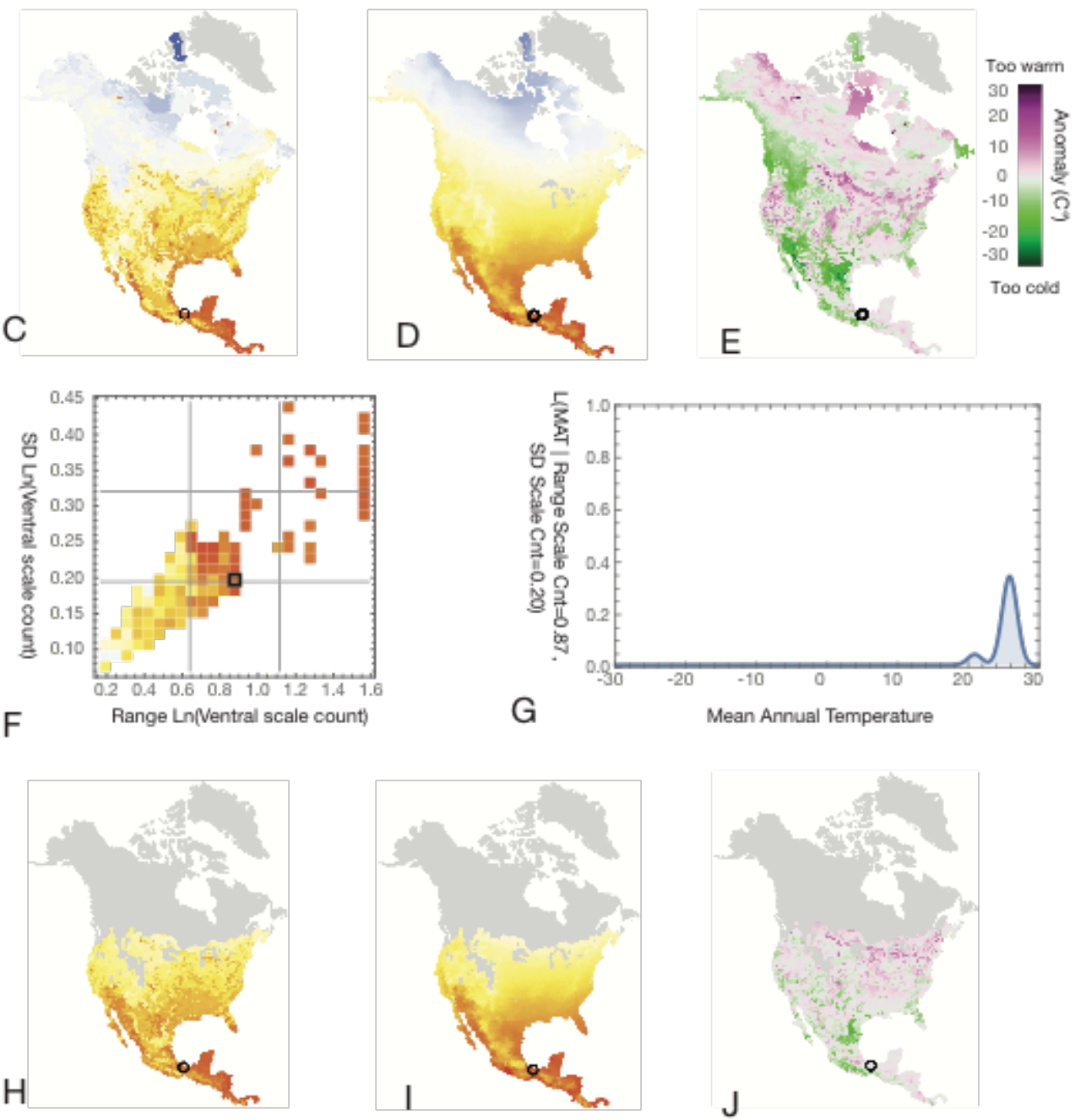

1001

1002

1003 
1007 Programing Language. To demonstrate these models in R, we will work with spatial data.

1008 There are special functions in two packages, raster and $s p$, that allow for relatively quick 1009 processing of spatial information (Bivand et al. 2015, Hijmans 2015, Pebesma and

1010 Bivand 2005). We will use climate data from the worldclim database (Hijmans et al.

1011 2005) and we will use trait data body mass and hypsodonty, from the PanTHERIA

1012 database (Jones et al. 2009) and from Eronen et al. (2010b). The code below in the gray

1013 boxes can be typed directly into an R console or can be entered into an R script file. The

1014 blue color indicates that the word is a function. The green color indicates that the text is a

1015 character string and the bright blue indicates that the text is recognized as a number. To

1016 start the analysis, load the two required libraries. If they are not installed yet on your

1017 computer, install them with the function install.packages().

1018 library(raster)

1019 \#\# Loading required package: sp

1020 library(sp)

1021

1022 Load the sampling locations and look at the first six rows of data with the functions

1023 read.csv() and head(). The first function read.csv() is a wrapper for another function

1024 called read.table(), which can be used in place of read.csv(), if the data are in tab

1025 delimited format. Use the help() function to see the documentation associated with each

1026 function. 

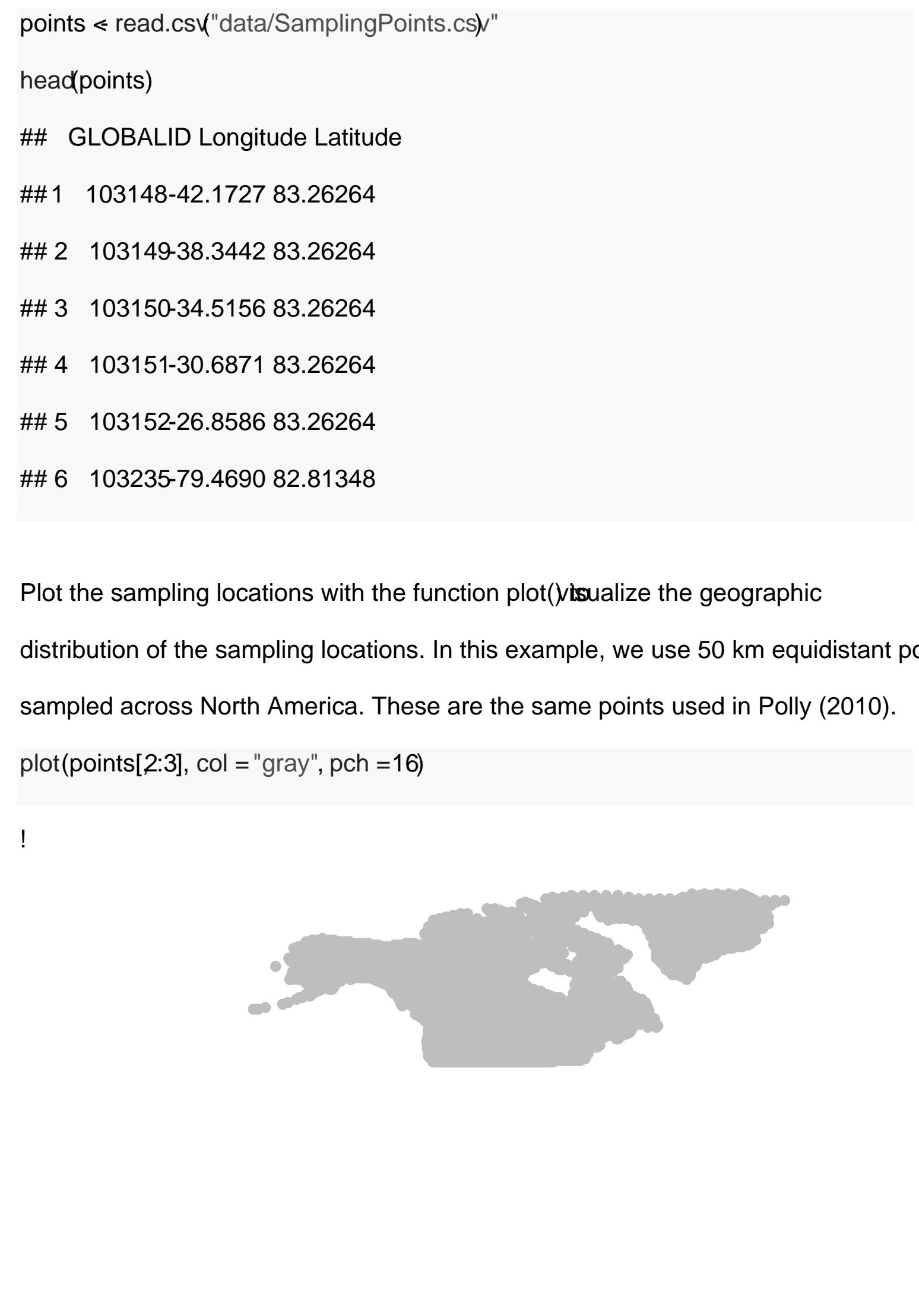





















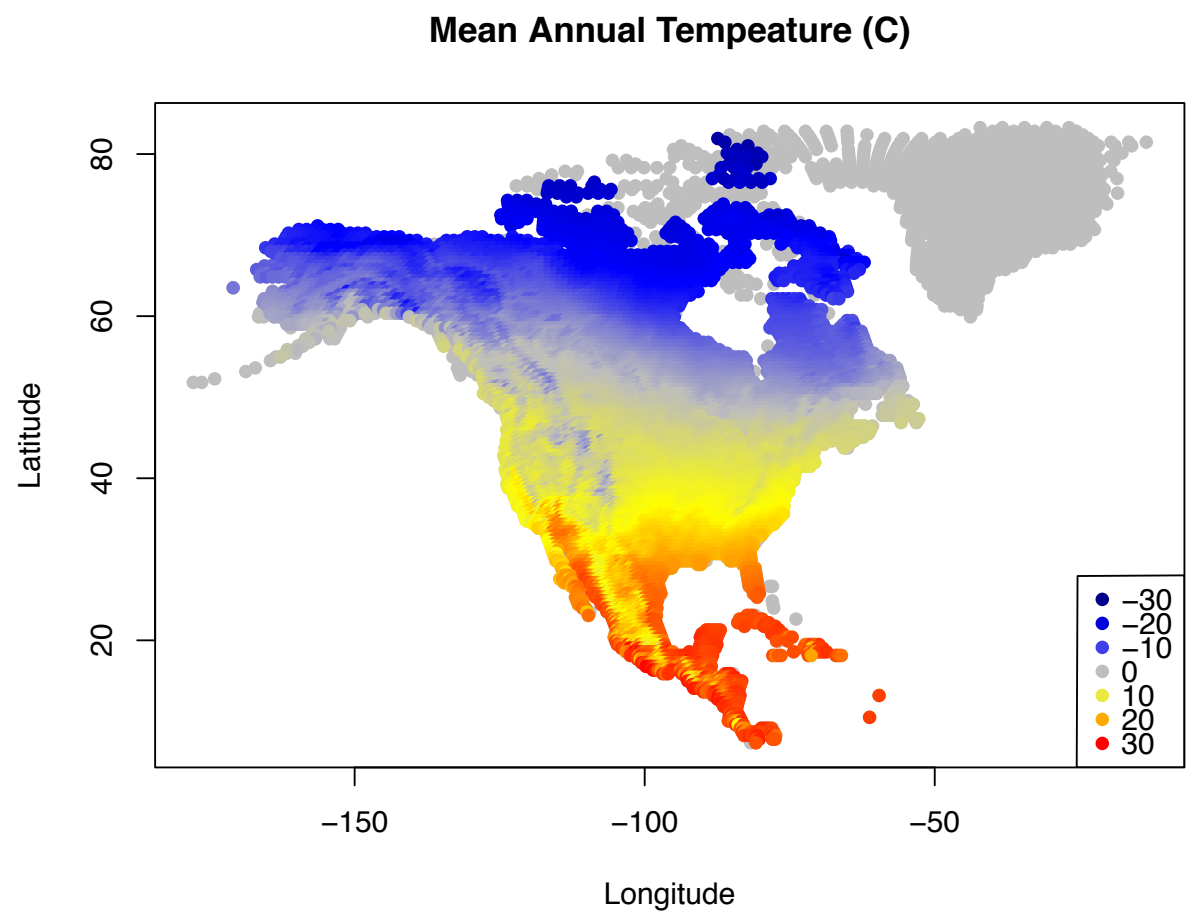

1355

1356 We plot the anomaly to visualize the difference between the estimated and actual Mean 1357 annual Temperature.

$1358 \operatorname{plot}($ points[,2:3], col = "gray", pch = 16)

1359 anom $<$ - temperature - modmax

1360 colfunc_anom <- colorRampPalette(c("purple", "grey", "green")) $(\max ($ anom, na.rm =

$1361 \mathrm{~T})-\min ($ anom, na.rm $=\mathrm{T}))[1+\operatorname{anom}-\min ($ anom, na.rm $=\mathrm{T})]$

1362 points(points[richness $>$ cutoff, 2:3], col = colfunc_anom[richness $>$ cutoff], pch $=16$ )

1363 legend $(-31.5,61$, legend $=\mathrm{h} \$$ breaks $/ 10, \mathrm{pch}=16, \mathrm{col}=$ colorRampPalette(c("purple", 1364 "grey", "green"))(length(h\$breaks)))

1365 


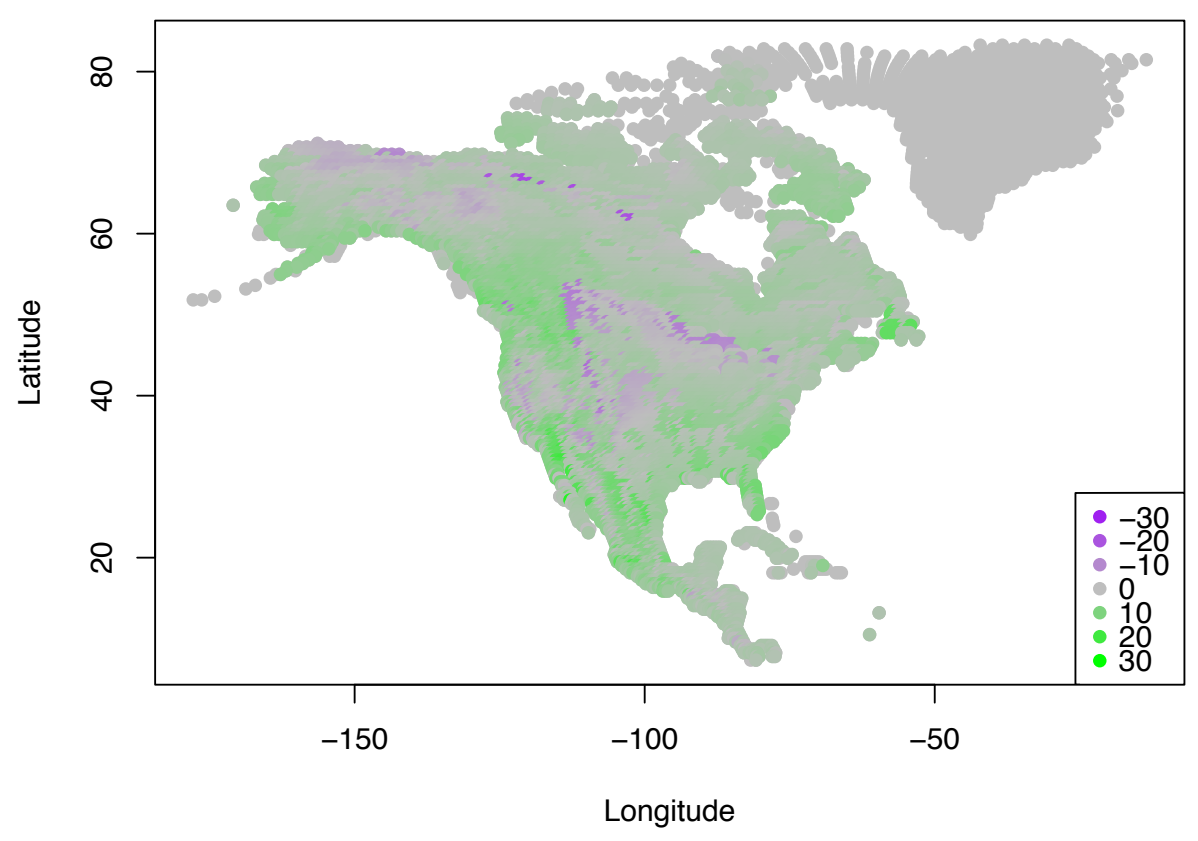

1366

1367 The anomaly between the estimated Mean Annual Temperature and the actual Mean

1368 Annual Temperature shows that most of the temperature estimates are less that one 1369 degree $\mathrm{C}$.

1370

APPENDIX I. REFERENCES

1372 Bivand, R. S., Pebesma, E. \& Gomez-Rubio, V. (2013). Applied spatial data analysis 1373 with R, Second edition. New York, NY: Springer.

1374 Eronen, J., Puolamaki, K., Liu, L., Lintulaakso, K., Damuth, J., Janis, C. \& Fortelius, 1375 M. (2010). Precipitation and large herbivorous mammals I: estimates from 1376 present-day communities. Evolutionary Ecology Research, 12, 217-233.

1377 Hijmans, R. J. (2015). raster: Geographic Data Analysis and Modeling. R package 1378 version 2.3-40. 
1379 Hijmans, R. J., Cameron, J. L., Parra, P. G., Jones, P. G. \& Jarvis, A. (2005). Very 1380 high resolution interpolated climate surfaces for global land areas.

1381 International Journal of Climatology, 25, 1965-1978.

1382 Jones, K. E., Bielby, J., Cardillo, M., Fritz, S. A., O'Dell, J., Orme, C. D. L., Safi, K., et al.

1383 (2009). PanTHERIA: a species-level database of life history, ecology, and 1384 geography of extant and recently extinct mammals. Ecology, 90, 2648-

2648.

1386 Lawing, A. M., Head, J. J. \& Polly, P. D. (2012). The ecology of morphology: the 1387 ecometrics of locomotion and macroenvironment in North American snakes. 1388 In J. Louys (Eds). Paleontology in Ecology and Conservation (pp. 117-146). 1389 Berlin: Springer Berlin Heidelberg.

1390 Pebesma, E. J. \& Bivand, R. S. (2005). Classes and methods for spatial data in R. $R$ $1391 \quad$ News, 5, 2.

1392 Polly, P. D. \& Head, J. J. (2015). Measuring Earth-life transitions: ecometric analysis 1393 of functional traits from late Cenozoic vertebrates. In P. D. Polly, J. J. Head, 1394 \& D. L. Fox (Eds.), Earth-Life Transitions: Paleobiology in the Context of 1395 Earth System Evolution (pp. 21-46). The Paleontological Society Papers 21. 1396 New Haven, CT: Yale Press. 